\title{
Influence of sucrose on growth and sensitivity of Candida albicans alone and in combination with Enterococcus faecalis and Streptococcus mutans to photodynamic therapy
}

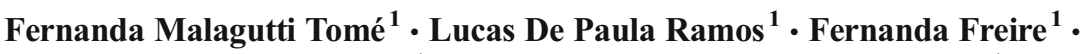 \\ Cristiane Aparecida Pereira ${ }^{1}$ - Ingrid Christine Barbosa de Oliveira ${ }^{1}$. \\ Juliana Campos Junqueira ${ }^{1}$ • Antonio Olavo Cardoso Jorge ${ }^{1} \cdot$ Luciane Dias de Oliveira $^{1}$
}

Received: 13 May 2015 / Accepted: 29 March 2017 /Published online: 7 April 2017

(C) Springer-Verlag London 2017

\begin{abstract}
This study has evaluated the effects of photodynamic inactivation (PDI) using erythrosine as photosensitizer and green light-emitting diode (LED) on biofilms of Candida albicans alone and in combination with Enterococcus faecalis and Streptococcus mutans. We have also evaluated the effect of sucrose on biofilm formation and bacterial growth and sensitivity to PDI. Biofilms were formed in suspension of $10^{6}$ cells $/ \mathrm{ml}$ on plates before being grown in broth culture with and without sucrose and incubated for $48 \mathrm{~h}$. Next, the treatment was applied using erythrosine at a concentration of $400 \mu \mathrm{M}$ for $5 \mathrm{~min}$ and green LED $(532 \pm 10 \mathrm{~nm})$ for $3 \mathrm{~min}$
\end{abstract}

Fernanda Malagutti Tomé

fmtome@gmail.com

Lucas De Paula Ramos

lucas93paula@hotmail.com.br

Fernanda Freire

fefreire21@hotmail.com

Cristiane Aparecida Pereira

cristiane.pereira@fosjc.unesp.br

Ingrid Christine Barbosa de Oliveira

ingrid.oliveira@fosjc.unesp.br

Juliana Campos Junqueira

juliana@ fosjc.unesp.br

Antonio Olavo Cardoso Jorge

olavojorge@ fosjc.unesp.br

Luciane Dias de Oliveira

luciane@fosjc.unesp.br

1 Department of Biosciences and Oral Diagnosis, São Paulo State University (Unesp), Institute of Science and Technology, São José dos Campos, Francisco José Longo 777, São Dimas, São José dos Campos, SP 12245-000, Brazil on biofilms alone and in combination. The plates were washed and sonicated to disperse the biofilms, and serial dilutions were carried and aliquots seeded in Sabouraud agar before incubation for $48 \mathrm{~h}$. Next, the colony-forming units per milliliter $\left(\mathrm{CFU} / \mathrm{ml} ; \log _{10}\right)$ were counted and analyzed statistically (ANOVA, Tukey test, $P \leq 0.05$ ). Results show that $S$. mutans favors the growth of $C$. albicans in biofilms with sucrose, with treatment not being effective. However, when the biofilm was grown without sucrose, we found a reduction in biofilm formation and a significant decrease in the PDI treatment $(P<0.0001)$. In conclusion, both growth and sensitivity to PDI in biofilms of $C$. albicans are strongly influenced by bacterial combination, and the presence of sucrose affected directly the growth and sensitivity of the biofilm to PDI as sucrose is the substrate for construction of the exopolysaccharide matrix.

Keywords Biofilm - Sucrose - Photodynamic therapy · Enterococcus faecalis $\cdot$ Streptococcus mutans $\cdot$ Candida albicans

\section{Introduction}

Biofilms develop after primary colonizing microorganisms adhere to inert or chemically conditioned surfaces. During biofilm maturation, new microorganism species establish as secondary colonizers on the top of the earlier layers. The structure and integrity of a biofilm is secured by the production of macromolecular extracellular substances. Depending on the species composition, there is intense inter- and intraspecies communication in polymicrobial oral biofilms $[1,2]$. Oral microbial biofilms may contain several hundred species, 
and their composition can differ significantly between individuals $[3,4]$.

Because of the importance of the microbial interactions, several studies have been conducted with mixed biofilms. Cruz et al. [5] further investigated how Enterococcus faecalis and Candida albicans affect each other in the context of an infection. Shekh and Roy [6] reported the purification and characterization of an antifungal protein produced by $E$. faecalis that shows broad-spectrum activity against the indicator organism, multidrug-resistant $C$. albicans, with negligible hemolytic activity. Brusca et al. [7] used mathematical modeling to study the potential interaction between $C$. albicans and Streptococcus mutans and to describe the mechanisms of interaction between both microorganisms.

Microorganisms are found in the nature forming biofilms, which are organized structured communities enclosed within a matrix of extracellular material. Biofilm cells are phenotypically different from planktonic cells as the structure of the former confers resistance to antifungal agents, which is related to the limited diffusion of the agent through the extracellular polysaccharide matrix or to phenotypic and genotypic alterations [8].

In view of the increase in opportunistic infections caused by species of the genus Candida in immune-suppressed patients, and the consequent emergence of strains resistant to conventional antifungal agents, new treatment options for oral candidoses are required to improve the therapeutic arsenal. In this respect, photodynamic inactivation (PDI) has been proposed as a new option to reduce yeasts of the genus Candida in the oral cavity [8-12].

PDI is based on the concept that a non-toxic dye, known as a photosensitizer, may be located preferentially in certain tissues or cells and subsequently activated by harmless visible light to produce reactive oxygen species which can kill cells binding to the photosensitizer. Numerous published studies have demonstrated that PDI is highly effective in the inactivation of fungi in vitro [13-16]. Additionally, it is believed that the development of resistance by microorganisms to PDI is an unlikely event as this is considered a typical multitarget process, which is different compared to most antifungal agents [17].

Clearly, the structure of the polysaccharide matrix can play a critical role in the virulence of plaque biofilms by influencing their physical and biochemical properties. It can enhance adherence of microorganisms, promote coherence, act as reserve source of energy, protect microorganisms from inimical influences, and affect the diffusion of substances into and out of the biofilm. In fact, sucrose is the raw material for the construction of the polysaccharide matrix [18-20].

Based on the above findings, the presence of mixed biofilm and influence of sucrose on the development and resistance of bacteria seem to affect their response to photodynamic therapy. This is the first study to report the action of PDI considering the interactions of microorganisms and biofilm growth with sucrose and without sucrose. The objective of this study was to analyze the sensitivity of $C$. albicans alone and in association with $E$. faecalis and $S$. mutans with and without sucrose to photodynamic therapy using erythrosine dye and green light-emitting diode (LED).

\section{Materials and methods}

\section{Preparation of the microorganism suspensions}

Three reference strains (American Type Culture Collection, ATCC), namely, C. albicans (ATCC 18804), E. faecalis (ATCC 29212), and S. mutans (ATCC 35688), were used in the study.

C. albicans was plated onto Sabouraud dextrose agar (HiMedia, Mumbai, India) and S. mutans and E. faecalis onto brain heart infusion (BHI) agar (Acumedia, Neogen, Lasing, MI, USA) incubated at $37^{\circ} \mathrm{C}$ for $24 \mathrm{~h}$ to reactivate the frozen strains. All experiments with $S$. mutans were incubated at $37^{\circ} \mathrm{C}$ and $5 \% \mathrm{CO}_{2}$.

After incubation, the culture seeded in agar was suspended in sterile BHI broth (Acumedia, Neogen, Lasing, MI, USA) with or without $5 \%$ of sucrose. This suspension was standardized using a spectrophotometer (B582, Micronal, São Paulo, SP, Brazil) adjusting the density of suspension equivalent to $10^{6}$ cells $/ \mathrm{ml}$. The optical density and wavelength parameters used were, respectively, 0.284 and $530 \mathrm{~nm}$ for C. albicans, 0.620 and $398 \mathrm{~nm}$ for S. mutans, and 0.298 and $398 \mathrm{~nm}$ for E. faecalis.

\section{Biofilm formation}

After standardization to grow the biofilms, the suspensions of each microorganism were distributed into 96 wells of the microtiter plate with high-transparency polystyrene and smooth and polished well walls, sterilized by gamma ray (Costar Corning, New York, USA), in a total volume of $250 \mu \mathrm{l}$, which was divided into equal proportions of each microorganism in mixed biofilms. We emphasized the presence or absence of sucrose in the broth suspension, thus creating two evaluation biases. The groups and volumes were accordingly seeded as shown in Table 1 . The plates were incubated for $24 \mathrm{~h}$ at $37^{\circ} \mathrm{C}$ in a microaerophilic atmosphere by using a $3 \mathrm{D}$ shaker (GyroTwisterTM 3-D Shaker, Labnet, NJ, USA).

\section{Photosensitizer and LED}

For sensitization of biofilms, erythrosine (ER) was used as photosensitizer (PS) (Sigma-Aldrich) at absorption wavelengths of $500-550 \mathrm{~nm}$ and concentration of $400 \mu \mathrm{M}$. The PS solution was prepared by dissolving the powdered dye in 
Table 1 Distribution of experimental groups

\begin{tabular}{|c|c|c|c|c|c|}
\hline \multicolumn{2}{|c|}{ Groups } & $\mathrm{Ca}$ & $\mathrm{Ca}+\mathrm{Sm}$ & $\mathrm{Ca}+\mathrm{Ef}$ & $\mathrm{Ca}+\mathrm{Ef}+\mathrm{Sm}$ \\
\hline \multicolumn{2}{|c|}{ Volumes } & $250 \mu \mathrm{l}$ & $125+125 \mu l$ & $125+125 \mu l$ & $83.3+83.3+83.3 \mu 1$ \\
\hline I & Control group $(\mathrm{P}-\mathrm{L}-)$ & $N=10$ & $N=10$ & $N=10$ & $N=10$ \\
\hline II & Photosensitizer group $(\mathrm{P}+\mathrm{L}-)$ & $N=10$ & $N=10$ & $N=10$ & $N=10$ \\
\hline III & Light group (P-L+) & $N=10$ & $N=10$ & $N=10$ & $N=10$ \\
\hline IV & PDI group (P+L+) & $N=10$ & $N=10$ & $N=10$ & $N=10$ \\
\hline
\end{tabular}

Volumes: values used for each standardized suspension, in each experimental group in the biofilm assembly Ca Candida albicans isolated, $\mathrm{Ca}+\mathrm{Sm}$ C. albicans combined with Streptococcus mutans, Ca + Ef C. albicans combined with $E$. faecalis, $C a+E f+S m C$. albicans combined with $E$. faecalis and $S$. mutans
PBS, filtered through a sterile $0.22-\mu \mathrm{m}$ filter (Millipore, São Paulo, Brazil), and stored in the dark before use.

A green light-emitting diode (LED) (MMOptics, São Carlos, SP, Brazil) was used as light source operating at wavelengths of $532 \pm 10 \mathrm{~nm}$ (corresponding to the maximum absorption of ER), output power of $90 \mathrm{~mW}$, energy of $5.4 \mathrm{~J}$, fluence rate of $237 \mathrm{~mW} / \mathrm{cm}^{2}$, and fluence of $14 \mathrm{~J} / \mathrm{cm}^{2}$ for $90 \mathrm{~s}$. The irradiated area of the biofilm was $0.38 \mathrm{~cm}^{2}$. The temperature at the bottom of the 96-well microtiter plates was monitored by using an infrared thermometer (MX4, Raytek, Sorocaba, SP, Brazil), with no increase being observed in the temperature after LED irradiation.

\section{Treatment}

The biofilms were submitted to different experimental conditions, namely, I-control group ( $\mathrm{P}-\mathrm{L}-$ ), using $250 \mu$ l of sterile saline solution $[0.9 \%$ sodium chloride $(\mathrm{NaCl})]$; II - photosensitizer group $(\mathrm{P}+\mathrm{L}-)$, using sensitization with $250 \mu$ of ER at a concentration of $400 \mu \mathrm{M}$ for $5 \mathrm{~min}$; III-light group (P-L+), using $250 \mu \mathrm{l}$ of $0.9 \% \mathrm{NaCl}$ and LED irradiation for $90 \mathrm{~s}$; and IV-PDI group $(\mathrm{P}+\mathrm{L}+)$ using sensitization with $250 \mu$ of ER at a concentration of $400 \mu \mathrm{M}$ for 5 min and LED irradiation for $90 \mathrm{~s}$.

The plates with photosensitizer solution were shaken for 5 min (pre-irradiation time) in an orbital shaker (Solab, Piracicaba, Brazil). The irradiation of biofilms was performed in the dark under aseptic conditions in a laminar flow hood. During irradiation, the plates were covered with a black matte screen with an orifice of the same size as the wells to prevent light from reaching the neighboring wells.

\section{Determination of colony-forming units per milliliter}

After irradiation of the biofilms, the photosensitizer solution was washed out with $250 \mu \mathrm{l} 0.9 \% \mathrm{NaCl}$. Next, the biofilms were disaggregated in $0.9 \% \mathrm{NaCl}$ with ultrasonic sonicator (Sonics Vibra-Cell, CT, USA) for $30 \mathrm{~s}$. Biofilm suspensions were serially diluted in $0.9 \% \mathrm{NaCl}$ to produce dilutions of $10^{-1}$ to $10^{-4}$ times the original concentration. Aliquots of
$0.1 \mathrm{ml}$ of each dilution were seeded on agar plates according to each microorganism of the biofilm. Sabouraud dextrose agar (HiMedia) with $50 \mathrm{mg} / \mathrm{l}$ chloramphenicol (União Química, São Paulo, Brazil) was used for C. albicans, Mitis Salivarius Agar (Difco, Detroit, USA) supplemented with $0.2 \mathrm{IU} / \mathrm{ml}$ bacitracin (União Química, São Paulo, Brazil) and $15 \%$ sucrose was used for $S$. mutans, and m-Enterococcus agar (Difco, Detroit, USA) was used for $E$. faecalis. The number of colony-forming units per milliliter $(\mathrm{CFU} / \mathrm{ml})$ was determined after $48 \mathrm{~h}$ of incubation. The results were logtransformed $\left(\log _{10}\right)$ and analyzed by using ANOVA and Tukey's test, with a $P$ value less than 5\% indicating statistically significant difference. To validate the mixed biofilms, the counting of $C$. albicans, E. faecalis, and $S$. mutans was performed separately.

\section{Influence of sucrose on biofilm and effects of PDI}

The previously described procedures were repeated by using BHI broth (Acumedia) without the addition of sucrose in order to verify the influence of sucrose on the production of the exopolysaccharide matrix by $S$. mutans, and consequently its influence on both biofilm and effects of PDI.

\section{Statistical analysis}

The results were $\log$-transformed $\left(\log _{10}\right)$ and analyzed by using analysis of variance (ANOVA) and Tukey's test. Statistically significant difference was set at $p<0.05$.

\section{Results}

This study was divided into two parts, biofilms grown with and without sucrose submitted to different experimental conditions of PDI assays. Mean and standard deviation values of $\mathrm{CFU} / \mathrm{ml}\left(\log _{10}\right)$ obtained under different experimental conditions for each biofilm group are shown in Figs. 1, 2, 3, and 4. The mean values of reduction $\left(\mathrm{CFU} \log _{10}\right)$ and $P$ values obtained for growth interactions are shown in Table 2. Table 3 


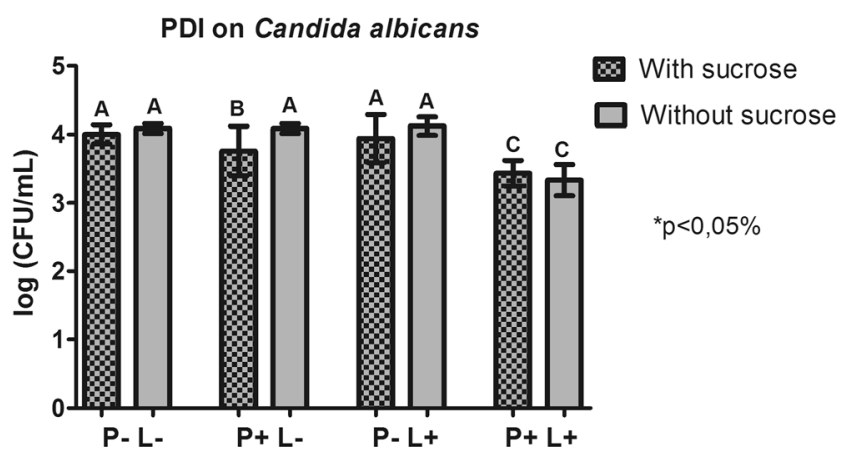

Fig. 1 Mean $(n=10)$ and standard deviation values of CFU/ml $\left(\log _{10}\right)$ of biofilms formed by C. albicans (C) with and without sucrose under the following different experimental conditions: control ( $\mathrm{P}-\mathrm{L}-, n=10)$, with $250 \mu$ of $0.9 \% \mathrm{NaCl} ;(\mathrm{P}+\mathrm{L}-, n=10)$, sensitization with $250 \mu \mathrm{l}$ of ER at concentration of $400 \mu \mathrm{M}$ for $5 \mathrm{~min}$; (P-L+, $n=10)$, treated with $250 \mu \mathrm{l}$ of $0.9 \% \mathrm{NaCl}$ and LED irradiation for $90 \mathrm{~s}$; and $(\mathrm{P}+\mathrm{L}+, n=10)$, sensitization with $250 \mu \mathrm{l}$ of ER at concentration of $400 \mu \mathrm{M}$ for $5 \mathrm{~min}$ and LED irradiation $90 \mathrm{~s}$. Tukey's test was used for each group tested. Values followed by different capital letters differed significantly between the experimental conditions $(P<0.05)$

shows the mean values of reduction $\left(\mathrm{CFU} \log _{10}\right)$ and $P$ values for biofilms submitted to PDI mediated by ER $(\mathrm{P}+\mathrm{L}+)$ compared to untreated control biofilms $(\mathrm{P}-\mathrm{L}-)$.

As shown in Fig. 1, no statistical difference was found in the growth of $C$. albicans biofilms with or without sucrose. The efficiency of PDI for C. albicans biofilms was statistically significant under both conditions, with $P$ values $=0.0200$ with sucrose and $<0.0001$ without sucrose (Table 2 ). Thus, one can see that sucrose had no influence on the growth of C. albicans biofilm.

The combination of $C$. albicans with E. faecalis had lower growth in the biofilm (Fig. 2). But the reduction of biofilm in the PDI group was not significant with the presence of sucrose

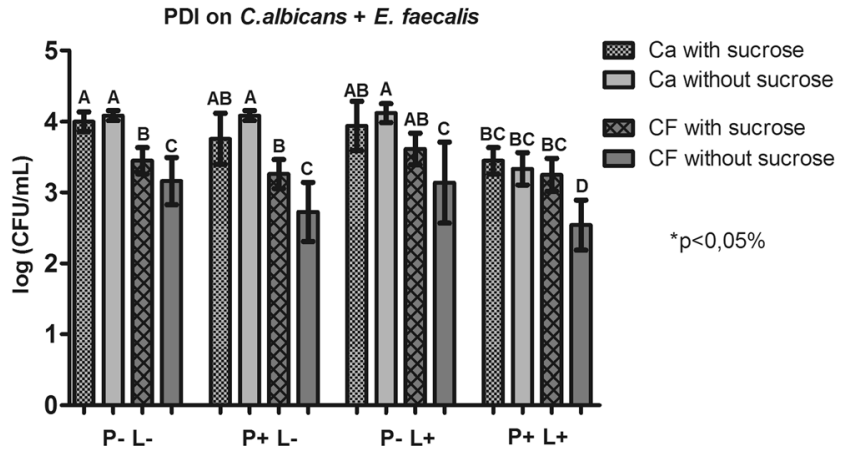

Fig. 2 Mean $(n=10)$ and standard deviation values of CFU/ml $\left(\log _{10}\right)$ of biofilms formed by C. albicans (C) compared to the C. albicans + $E$. faecalis combination with and without sucrose under the following different experimental conditions: control ( $\mathrm{P}-\mathrm{L}-, n=10)$, treated with $250 \mu \mathrm{l}$ of $0.9 \% \mathrm{NaCl} ;(\mathrm{P}+\mathrm{L}-, n=10)$, sensitization with $250 \mu \mathrm{l}$ of ER at concentration of $400 \mu \mathrm{M}$ for $5 \mathrm{~min}$; $(\mathrm{P}-\mathrm{L}+, n=10)$, treated with $250 \mu \mathrm{l}$ of $0.9 \% \mathrm{NaCl}$ and LED irradiation for $90 \mathrm{~s}$; and $(\mathrm{P}+\mathrm{L}+, n=10)$, sensitization with $250 \mu \mathrm{l}$ of ER at concentration of $400 \mu \mathrm{M}$ for $5 \mathrm{~min}$ and LED irradiation for $90 \mathrm{~s}$. Tukey's test was used for each group tested. Values followed by different capital letters differed significantly between the experimental conditions $(P<0.05)$

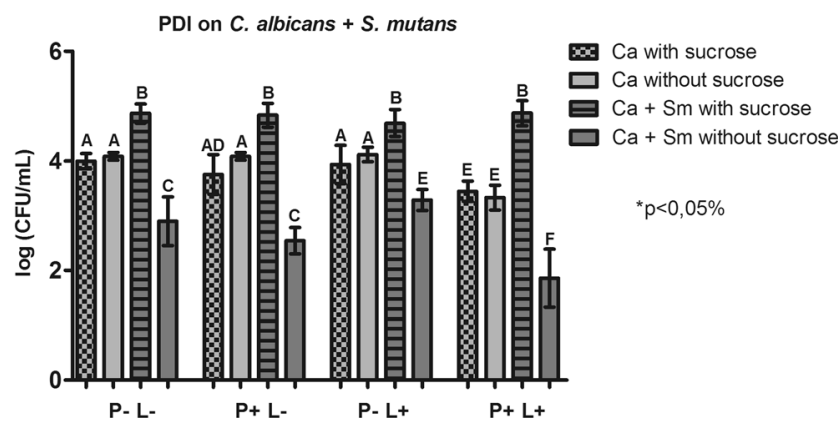

Fig. 3 Mean values $(n=10)$ and standard deviation of CFU $/ \mathrm{ml}\left(\log _{10}\right)$ of biofilms formed by $C$. albicans $(\mathrm{C})$ compared with $C$. albicans + S. mutans $(\mathrm{CM})$ association both with and without sucrose for different experimental conditions: control ( $\mathrm{P}-\mathrm{L}-, n=10)$, treated with $250 \mu \mathrm{l}$ of $0.9 \% \mathrm{NaCl} ;(\mathrm{P}+\mathrm{L}-, n=10)$ : sensitization with $250 \mu \mathrm{l}$ of ER at a concentration of $400 \mu \mathrm{M}$ for $5 \mathrm{~min}$; $(\mathrm{P}-\mathrm{L}+, n=10)$ : treated with $250 \mu \mathrm{l}$ of $0.9 \% \mathrm{NaCl}$ and LED irradiation for $90 \mathrm{~s}$; $(\mathrm{P}+\mathrm{L}+, n=10)$, sensitization with $250 \mu \mathrm{l}$ of ER at a concentration of $400 \mu \mathrm{M}$ for $5 \mathrm{~min}$ and LED irradiation for $90 \mathrm{~s}$. Tukey's test was used for each group tested. Values followed by different capital letters differed significantly among the experimental conditions $(P<0.05)$

$(P=0.2301)$, showing a significant reduction without it $(P=0.0002)$.

When $C$. albicans grown in combination with $S$. mutans (Fig. 3) in the presence of sucrose showed an increase in the biofilm growth, the treatment with PDI did not show efficiency. On the other hand, in the same biofilm grown without sucrose, there was a significant reduction in the biofilm treated with PDI $(P=<0.0001)$.

One can observe multiple species in the biofilm formed with $C$. albicans, E. faecalis, and S. mutans (Fig. 4), with the addition of sucrose increasing the growth of the yeast, but with no reduction of PDI assays. For biofilms formed without sucrose, one can see that there was a reduction in

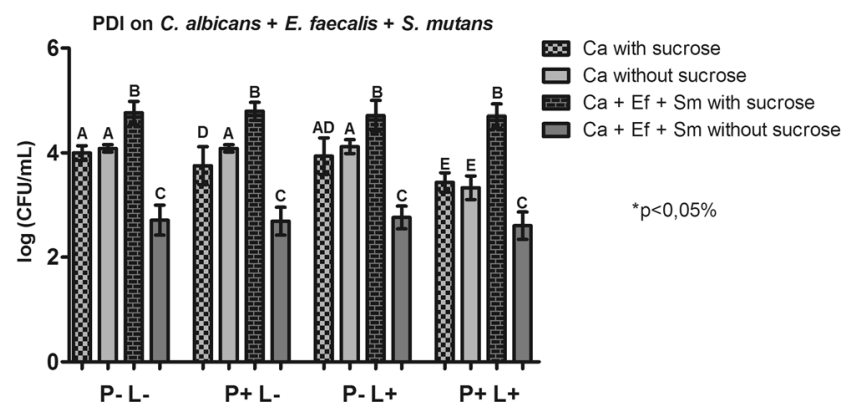

Fig. 4 Mean $(n=10)$ and standard deviation values of CFU/ml $\left(\log _{10}\right)$ of biofilms formed by $C$. albicans (C) compared to the $C$. albicans + S. mutans + E. faecalis $(\mathrm{CMF})$ combination with and without sucrose under the following different experimental conditions: control ( $\mathrm{P}-\mathrm{L}-$, $n=10)$, treated with $250 \mu \mathrm{l}$ of $0.9 \% \mathrm{NaCl} ;(\mathrm{P}+\mathrm{L}-, n=10)$, sensitization with $250 \mu \mathrm{l}$ of ER at concentration of $400 \mu \mathrm{M}$ for $5 \mathrm{~min}$; $(\mathrm{P}-\mathrm{L}+, n=10)$, treated with $250 \mu \mathrm{l}$ of $0.9 \% \mathrm{NaCl}$ and LED irradiation for $90 \mathrm{~s}$; and $(\mathrm{P}+\mathrm{L}+, n=10)$, sensitization with $250 \mu \mathrm{l}$ of ER at concentration of $400 \mu \mathrm{M}$ for $5 \mathrm{~min}$ and LED irradiation for $90 \mathrm{~s}$. Tukey's test was used for each group tested. Values followed by different capital letters differed significantly between the experimental conditions $(P<0.05)$ 
Table $2 \log _{10}$ results analyzed by $t$ test obtained for control biofilms, considering the growth of Candida albicans biofilm (C) alone versus combination with Enterococcus faecalis (CF), Streptococcus mutans (CM), and Streptococcus mutans and Enterococcus faecalis (CMF), with and without sucrose

\begin{tabular}{lllll}
\hline Groups & $\begin{array}{l}\text { With sucrose } \\
\log _{10}\end{array}$ & $* P$ value & $\begin{array}{l}\log _{10} \\
\text { Without sucrose }\end{array}$ & $* P$ value \\
\hline $\mathrm{C} \times \mathrm{CM}$ & 0.867 & $<0.0001$ & 1.19 & $<0.0001$ \\
$\mathrm{C} \times \mathrm{CF}$ & 0.552 & $<0.0001$ & 0.927 & $<0.0001$ \\
$\mathrm{C} \times \mathrm{CMF}$ & 0.763 & $<0.0001$ & 1.38 & $<0.0001$ \\
\hline
\end{tabular}

$* P>0.05$, statistically significant difference (ANOVA, Tukey's test)

the growth, but with no statistically significant reduction in the group treated with PDI.

Table 2 shows that the amount of $C$. albicans biofilm combined with $S$. mutans $\left(0.876 \log _{10}, P<0.0001\right)$ or of $C$. albicans with E. faecalis and $S$. mutans $\left(0.763 \log _{10}\right.$, $P<0.0001)$ in the presence of sucrose was greater than that of the biofilm formed by one yeast alone. However, when combined with $E$. faecalis, the growth was reduced $(0.552$ $\left.\log _{10}\right)(P<0.0001)$. In the absence of sucrose in the biofilm of $C$. albicans with $S$. mutans $\left(1.19 \log _{10}, P<0.0001\right)$, there was a lower growth compared to biofilm of $C$. albicans alone. This decrease was also observed in biofilms presenting combination of $C$. albicans with $E$. faecalis and $S$. mutans (1.38 $\left.\log _{10}, P<0.0001\right)$ and in biofilms of $C$. albicans combined with $E$. faecalis $\left(0927 \log _{10}, P<0.0001\right)$.

As shown in Table 3, the biofilms formed in the presence or absence of sucrose showed different sensitivities to PDI. In the presence of sucrose, only biofilms of $C$. albicans alone showed sensitivity to PDI, with a significant reduction $\left(\log _{10}\right.$ $0.5518, P=0.0200)$. However, in groups without sucrose, only the combination of $C$. albicans, $S$. mutans, and $E$. faecalis (CMF) showed no statistically significant reduction $\left(0.1080 \log _{10}\right)(P=0.8787)$.

Table $3 \log _{10}$ results of reduction analyzed by $t$ test obtained for biofilms submitted to PDT mediated by erythrosine dye $(\mathrm{F}+\mathrm{L}+)$ in relation to untreated control biofilms ( $\mathrm{F}-\mathrm{L}-$ ), considering Candida albicans (C) alone and combined with Enterococcus faecalis (CF) and Streptococcus mutans $(\mathrm{CM})$, with and without sucrose

\begin{tabular}{llllr}
\hline Groups & $\begin{array}{l}\text { With sucrose } \\
\log _{10} \text { reduction }\end{array}$ & $* P$ value & $\begin{array}{l}\text { Without sucrose } \\
\log _{10} \text { reduction }\end{array}$ & $* P$ value \\
\hline $\mathrm{C}$ & 0.5518 & 0.02 & 0.754 & $<0.0001$ \\
$\mathrm{CF}$ & 0.2005 & 0.2301 & 0.619 & 0.0002 \\
$\mathrm{CM}$ & 0.0051 & $>0.9999$ & 1.039 & $<0.0001$ \\
$\mathrm{CMF}$ & 0.0581 & 0.9457 & 0.108 & 0.8787 \\
\hline
\end{tabular}

$* P>0.05$, statistically significant difference (ANOVA, Tukey's test)

\section{Discussion}

Biofilms formed by only $C$. albicans were sensitive to PDI mediated by ER as photosensitizer and green LED, both with and without sucrose. PDI significantly reduced the amounts of yeast by $0.5518 \log _{10}(P=0.0200)$ and $0.7540 \log _{10}(P \leq 0.0001)$, respectively, with and without sucrose. These results are corroborated by other similar studies. Costa et al. [21] evaluated the effect of PDI with ER and green LED on planktonic cultures and biofilms of C. albicans, reporting that biofilms were more resistant than the planktonic forms. Another study by Costa et al. [22] investigated the effects of PDI on C. albicans planktonic cultures and biofilms by using either Rose Bengal (RB) dye or ER with green LED, reporting that PDI was effective in reducing $C$. albicans.

Costa et al. [23] evaluated the effects of PDI on oral candidiasis in mice and in vitro regarding the adherence of yeast to oral epithelial cells (OECs), which were submitted to PDI with erythrosine $(400 \mu \mathrm{mol} / \mathrm{l})$ and green LED at $14.34 \mathrm{~J} / \mathrm{cm}^{-2}$. PDI reduced significantly the amount of yeast present in the lesions by $\left(0.73 \log _{10}\right)$ $(P=0.018)$ and the $C$. albicans adherence to OECs by $35 \%$ without damaging adjacent tissues $(P=0.045)$. The conclusion of this study was that PDI exhibited antifungal effects on C. albicans biofilms formed in vivo and reduced the capacity of $C$. albicans to adhere to OECs in vitro. A reduction of C. albicans after treatment with PDI was also observed.

The yeast $C$. albicans and the Gram-positive bacterium E. faecalis are both normal residents of the human oral microbiome, causing opportunistic disseminated infections in immunocompromised individuals. According to Garsin and Lorenz [24], who used a nematode infection model, that co-infection resulted in less pathology and less mortality than the infection with either species alone. This finding was partly explained by an inter-kingdom signaling event in which a bacterial-derived product inhibits hyphal morphogenesis of C. albicans.

In this study, when $C$. albicans was combined with E. faecalis, the yeast showed lower growth with and without sucrose. Also, C. albicans was not sensitive to PDI in the group with sucrose (reduction of $\left.0.2005 \log _{10}\right)(P=0.2301)$, but was in the group without sucrose (reduction of 0.6190 $\left.\log _{10}\right)(P=0.0002)$. In a research study conducted by Shekh and Roy [6], an anti-Candida factor produced by E. faecalis (protein ACP) was purified and partially characterized. The ACP showed broad-spectrum activity against different multidrug-resistant strains of $C$. albicans. This finding helps explain the results of our study because the growth of $C$. albicans was reduced in the presence of E. faecalis. However, it is not clear why the yeast did not show significant reduction following PDI. 
When $C$. albicans was combined with $S$. mutans with sucrose, it was found that growth increased $\left(0.867 \log _{10}\right)$ $(P>0.0001)$ and the yeast was not sensitive to PDI $\left(0.0051 \log _{10}\right)(P>0.9999)$. This seems to increase the production of the extracellular polysaccharide (EPS) matrix by $S$. mutans, since we observed that the group without sucrose showed lower growth (1.19 $\left.\log _{10}\right)$ $(P<0.0001)$ and was sensitive to PDI $\left(1.03 \log _{10}\right)$ $(P>0.0001)$. These data demonstrate that the more complex the composition of the biofilms, the more resistant they seem to be to the PDI process. The interactions between different matrix polymers produced by different microorganisms might result in a more viscous matrix $[18,20]$.

Clearly, the structure of the polysaccharide matrix can play a critical role in the virulence of plaque biofilms by influencing their physical and biochemical properties. It can enhance adherence of microorganisms, promote coherence, act as reserve source of energy, protect microorganisms from inimical influences, and affect diffusion of substances into and out of the biofilm [18]. Thus, it is likely that this matrix affects the absorption of erythrosine in the biofilm and the light penetration as well, thereby preventing the photodynamic action.

According to Falsetta et al. [25], C. albicans cells are frequently detected along with heavy infection by $S$. mutans in biofilms. The authors showed that the ability of these organisms to form biofilms together is enhanced in vitro and in vivo. The presence of $C$. albicans increases the production of EPS so that co-species biofilms accumulate more biomass and harbor more viable $S$. mutans cells than single-species biofilms.

The resulting three-dimensional biofilm architecture displays sizeable $S$. mutans microcolonies surrounded by fungal cells, which are enmeshed in a dense EPS-rich matrix. According to Sztajer et al. [26], in vitro data also revealed that glucosyltransferase-derived EPS is a key mediator of cospecies biofilm development and that co-existence with C. albicans induces the expression of virulence genes in S. mutans. In this study, it was also found that Candida-derived $\beta 1,3$-glucans contribute to the EPS matrix structure, whereas fungal mannan and $\beta$-glucan provide sites for binding and activity of glucosyltransferases. Altogether, they demonstrate a novel mutualistic bacterium-fungus relationship occurring at a clinically relevant site to amplify the severity of a ubiquitous infectious disease. [25].

The results of this study allow us to conclude that both growth and sensitivity of $C$. albicans biofilm to PDI are strongly influenced by the combination of this yeast with $S$. mutans in the biofilm. The presence of sucrose directly affects the growth and sensitivity of the biofilm as sucrose is the substrate for the synthesis of the EPS matrix.
Acknowledgements The authors would like to thank the State of São Paulo University (UNESP) for the resources and encouragement of this research.

\section{Compliance with ethical standards}

Conflicts of interest The authors declare that they have no conflict of interest.

Funding The authors declare that they did not receive funding for the development of this research.

Ethical procedures All ethical procedures were followed. Because the research used ATCC strains of microorganisms and did not involve any kinds of animal, the approval committee of ethics and informed consent do not apply to work.

\section{References}

1. Kuramitsu HK, He X, Lux R, Anderson MH, Shi W (2007) Interspecies interactions within oral microbial communities. Microbiol Mol Biol Rev 71(4):653-670. doi:10.1128/MMB12. 00024-07

2. Kolenbrander PE, Andersen RN, Blehert DS, Egland PG, Foster JS, Palmer RJ (2002) Communication among oral bacteria. Microbiol Mol Biol Rev 66(3):486-505. doi:10.1128/MMBR.66.3.486-505. 2002

3. Haffajee AD, Socransky SS (2006) Introduction to microbial aspects of periodontal biofilm communities, development and treatment. Periodontol 2000(42):7-12. doi:10.1111/j.1600-0757.2006. 00190.x

4. Mager DL, Ximenez-Fyvie LA, Haffajee AD, Socransky SS (2003) Distribution of selected bacterial species on intraoral surfaces. J Clin Periodontol 30(7):644-654. doi:10.1034/j.1600-051X.2003. 00376.x

5. Cruz MR, Graham CE, Gagliano BC, Lorenz MC, Garsin DA (2013) Enterococcus faecalis inhibits hyphal morphogenesis and virulence of Candida albicans. Infect Immun 81(1):189-200. doi: 10.1128/LAI.00914-12

6. Shekh RM, Roy U (2012) Biochemical characterization of an antiCandida factor produced by Enterococcus faecalis. BMC Microbiol 12(1):132. doi:10.1186/1471-2180-12-132

7. Brusca MI, Irastorza RM, Cattoni DI, Ozu M, Chara O (2013) Mechanisms of interaction between Candida albicans and Streptococcus mutans: an experimental and mathematical modelling study. Acta Odontol Scand 71(3-4):416-423. doi:10.3109/ 00016357.2012.690530

8. Seneviratne CJ, Jin L, Samaranayake LP (2008) Biofilm lifestyle of Candida: a mini review. Oral Dis 7:582-590. doi:10.1111/j.16010825.2007.01424.x

9. Souza RC, Junqueira JC, Rossoni RD, Pereira CA, Munin E, Jorge AOC (2010) Comparison of the photodynamic fungicidal efficacy ogf methylene blue, toluidine blue, malachite green and low-power laser irradiation alone against Candida albicans. Lasers Med Sci 3: 385-389. doi:10.1007/s10103-009-0706-Z

10. Branda SS, Vik S, Friedman L, Kolter R (2005) Biofilms: the matrix revisited. Trends Microbiol 13(1):20-26. doi:10.1016/j.tim. 2004.11.006

11. Hube B (2004) From comensal to pathogen: stage-and tissue-specific gene expression of Candida albicans. Curr Opin Microbiol 4: 336-334. doi:10.1016/j.mib.2004.06.003 
12. Souza SC, Junqueira JC, Balducci I, Ito-Koga CY, Munin E, Jorge AOC (2006) Photosensitization of different Candida species by low power laser light. Photochem Photobiol B Biol 83(1):34-38. doi: 10.1016/j.jphotobiol.2005.12.002

13. Lambrechts SA, Aalders MC, Marle JV (2005) Mechanistic study of the photodynamic inactivation of Candida albicans by a cationic porphyrin. Antimicrob Agents Chemother 5:2026-2034. doi:10. 1128/AAC.49.5.2026-2034.2005

14. Lam M, Jou PC, Lattif AA, Lee Y, Malbasa CL, Mukherjee PK et al (2011) Photodynamic therapy with Pc 4 induces apoptosis of Candida albicans. Photochem Photobiol 4:904-909. doi:10.1111/ j.1751-1097.2011.00938.x

15. Smijs TG, Pavel S (2011) The susceptibility of dermatophytes to photodynamic treatment with special focus on Trichophyton rubrum. Photochem Photobiol 1:2-13. doi:10.1111/j.1751-1097. 2010.00848.x

16. Freire F, Costa ACBP, Pereira CA, Junior MB, Junqueira JC, Jorge AOC (2013) Comparison of the effect of rose bengal- and eosin Ymediated photodynamic inactivation on planktonic cells and biofilms of Candida albicans. Lasers Med Sci 3:949-955. doi:10. 1007/s10103-013-1435-x

17. Lyon JP, Moreira LM, Moraes PC, Santos FV, Resende MA (2011) Photodynamic therapy for pathogenic fungi. Mycoses 5:265-271. doi:10.1111/j.1439- 507.2010.01966.x

18. Koo H, Xiao J, Klein MI, Jeon JG (2010) Exopolysaccharides produced by Streptococcus mutans glucosyltransferases modulate the establishment of microcolonies within multispecies biofilms. J Bacteriol 192(12):3024-3032. doi:10.1128/JB.01649-09

19. Koo H, Falsetta ML, Klein MI (2013) The exopolysaccharide matrix: a virulence determinant of cariogenic biofilm. J Dent Res 92(12):1065-1073. doi:10.1177/0022034513504218

20. Klein MI, DeBaz L, Agidi S, Lee H, Xie G, Lin AHM, Hamaker BR, Lemos JA, Koo H (2010) Dynamics of Streptococcus mutans transcriptome in response to starch and sucrose during biofilm development. PLoS One 5(10):e13478. doi:10.1371/journal.pone. 0013478

21. Costa AC, de Campos Rasteiro VM, Pereira CA, da Silva Hashimoto ES, Beltrame M Jr, Junqueira JC, Jorge AO (2011) Susceptibility of Candida albicans and Candida dubliniensis to erythrosine- and LED-mediated photodynamic therapy. Arch Oral Biol 56(11):1299-1305. doi:10.1016/j.archoralbio.2011.05.013

22. Costa AC, Rasteiro VM, Pereira CA, Rossoni RD, Junqueira JC, Jorge AO (2012) The effects of rose bengal- and erythrosinemediated photodynamic therapy on Candida albicans. Mycoses 55(1):56-63. doi:10.1111/j.1439-0507.2011.02042.x

23. Costa AC, Campos VMR, Hashimoto ESS, Araújo CF, Pereira CA, Junqueira JC, Jorge AO (2012) Effect of erythrosine- and LEDmediated photodynamic therapy on buccal candidiasis infection of immunosuppressed mice and Candida albicans adherence to buccal epithelial cells. Oral Surg Oral Med Oral Pathol Oral Radiol 114(1):67-74. doi:10.1016/j.0ooo.2012.02.002

24. Garsin DA, Lorenz MC (2013) Candida albicans and Enterococcus faecalis in the gut: synergy in commensalism? Gut Microbes 4(5): 409-415. doi:10.4161/gmic. 26040

25. Falsetta ML, Klein MI, Colonne PM, Scott-Anne K, Gregoire S, Pai CH, Gonzalez-Begne M, Watson G, Krysan DJ, Bowen WH, Koo H (2014) Symbiotic relationship between Streptococcus mutans and Candida albicans synergizes virulence of plaque biofilms in vivo. Infect Immun 82(5):1968-1981. doi:10.1128/IAI.0008714

26. Sztajer H, Szafranski SP, Tomasch J, Reck M, Nimtz M, Rohde M, Wagner-Döbler (2013) Cross-feeding and interkingdom communication in dual-species biofilms of Streptococcus mutans and Candida albicans. ISME J. doi:10.1038/ismej.2014.73 